\title{
Analyzing Service Failure Themes on Online Healthcare Product: Focusing on Online Consumers' Word-of-mouse
}

\author{
Sujin Oh \\ Dept. of Consumer Economics, Sookmyung Women's University, Korea
}

\begin{abstract}
The emergence of the Internet has provided a new outlet for consumers who experience service failure from products and services, augmenting the traditional options of entry, voice and action. Consumers' negative word of mouth through online (word-of-mouse or eWOM) far exceeds traditional word of mouth (WOM) in respect of its potential effectiveness, speed and spread. This paper tries to figure out the service failure themes in the health care industry by analyzing online word-of-mouse using the critical incidents technique (CIT). Complaint themes in the area of healthcare are identified and analyzed. The results identify that major complaint theme differed according to the site type. Also, the findings indicate that delivery and customer services are critical issues when consumer makes negative WOM.
\end{abstract}

Keywords: Service Failure, Consumers' complaint, Online word-of-mouth (word of mouse or eWOM), and Healthcare industry.

\section{INTRODUCTION}

The healthcare industry has and will continue to pay considerable attention to consumers because it is directly connected with their quality of life. Traditionally, when consumers experience service failure from the healthcare industry (especially from doctors), they have limited alternatives. Consumers may switch doctors or spread negative word-of-mouth (WOM) among their family, friends, colleagues, or acquaintances. Voicing of complaints has been traditionally seen as one of the three pillars of consumer redress, alongside switching suppliers and consumer activism [40]. Also, the speed and scope of the negative WOM is also limited. Negative WOM is the form of complaints that consumers express their experiences toward service failure. Despite the idea that service recovery has been key factor to customer loyalty [45], it has been easily overlooked in the healthcare industry so far.

However, the emergence of the Internet is sufficiently possible to change the situation. It could be empowered consumer by pressing firm to do recover their service failure. Today's consumers have access to more health information than ever before and consumers could to address their complaints to the third party virtual community in comparison with in the past addressing their complaints at the service provider level. According to the PEW Internet American Life survey [15] report, $80 \%$ of online consumers look to other consumers' and experts' health advice through the Internet. More than 70,000 websites disseminate health information and 50 million people seek health information [10]. Usually, health information

* Corresponding author,Email: sjoh@sookmyung.ac.kr Manuscript received Jul. 10, 2012; revised Sep 04, 2012; accepted Sep 14, 2012 seekers used the Internet to become informed, prepare for appointments, share information and to seek and provide support [16].

The Internet is quickly becoming the important new media and communication channel. Now consumers access to virtual community to share their opinions (word of mouse or eWOM). [33] explained that WOM was more trustworthy source than commercial sources of information controlled by companies because it was a personal source. Due to this WOM's characteristic, consumers have been to rely on WOM to reduce the level of perceived risk and the uncertainty that are often associated with service purchase decisions. Also, online wordof-mouse (eWOM) offers to the firm an attractive opportunity to learn about its environment by directly observing the flow of interpersonal communication [18].

At the same time, direct communication between consumers is more possible through online virtual communities far exceed by posting their experiences about products or services. Traditional communication (face-to-face) is not comparable to eWOM in respect of the effect, speed and spread of its range.

There has been relatively little research that has studied how consumers address health complaints (negative WOM) via online, while there have been a number of studies to develop measures of patient satisfaction and to evaluate the quality of provided health information [10], [13], [16], although less attention has been paid to the aspects of the service which are determinant of an overall positive or negative evaluation by consumers [17], [32].

Given the overall lack of knowledge and the relative newness of the topic of service failure (consumers' complaint) in the online healthcare environment, this study designed an exploratory one which was emphasizing discovery over confirmation. This study analyzed 202 consumers' complaint 
themes related to online health products and services in natural virtual third party web site in order to allow for a more comprehensive understanding of customer perceptions of online service failure. Complaints are analyzed using the critical incident technique (CIT). Complaints are categorized, and actual cases are used to illustrate negative eWOM toward healthcare products.

\section{REVIEW OF LITERATURE}

\subsection{Service Failure and Service Recovery}

Service recovery has been identified one of the key determinants to customer loyalty [45]. Service recovery refers to the actions a service provider takes in response to service failure [1], [17], [20]. A major goal of customer retention strategies is to stabilize the endangered relationship with dissatisfied customers by an effective service recovery policy [44]. A successful recovery can enhance customer retention [31].

In the past decades, most of the consumer satisfaction/quality area has focused on the disconformation of expectations [35], SERVQUAL [36], and equity theory [1], [17]. From this research, service quality is a key to consumer satisfaction. Furthermore, ineffective service recovery efforts have the potential to increase dissatisfaction [42]. If service failure happens, service recovery is the key method to recover from consumer dissatisfaction. [3] addressed the idea that the satisfaction with the process of the problem resolution is more important than initial service attributes in influencing overall satisfaction. Service failures and service recovery efforts also directly relate to consumer's complaint behavior [12].

Previous research has categorized consumer complaint themes toward online shopping products. [34] identified and categorized nine complaint themes into delivery related issues, consumer relations and services related issues, product and product supporting services related issues, order process related issues, billing and payment related issues, promotion and advertising related issues, website content and technology related issues, pricing related issues, and privacy related issues. [9] classified causes of complaints into eight themes; service failure (unresponsive to request to assistance; longer than average waiting time; contact possibilities; poor after-sale service, unfriendly); delivery problems (long delivery time; shipping contributes a lot to cost); unsatisfactory product quality or performance (product damaged/poor quality/ underwhelming performance); price (expensive, pricey, be wary of their financing program, interest rates are insanely high); security and trust issues (believe that this company rips people off); incorrect information (website did not provide exact information about the product); tracking and tracing (The site didn't provide the order status); and promotion.

This study draws on previous research to identify of consumer complaint themes in the online healthcare industry environment as well as the types of service failure that significantly affect customer complaints among different site types that all make consumers' negative eWOM.

\subsection{Negative Word-of-mouth (WOM) in the form of complaints \\ Word-of-mouth (WOM) is defined as "the informal} communication directed at other consumers about ownership and characteristics of particular goods and services and/or their sellers [47]. WOM has more potential impact than any other communication channel. [24] showed that WOM is seven times more effective than newspaper and magazine advertising, four times more effective than personal selling and twice as effective as advertising in influencing consumers to switch brands. WOM provides critical information about the service provider to consumers that helps consumers decided whether or not to patronize a firm. In this sense, WOM may prove beneficial to some firms in facilitating a brand switch or gaining new customer [30].

A substantial bodies of research indicated that WOM had a significant impact on consumer purchasing behavior. Early studies attributed this impact to normative social influences [43], [46]. However, subsequent research suggests that the informational aspect of social influence may also have a substantial impact on purchasing behavior [28]. WOM was often regarded as related to consumers' satisfaction or dissatisfaction with previous purchasing experience [5], [37], [48]. Consumers engage in WOM to satisfy their personal information needs [4]. Research has investigated the impact of negative WOM communication on consumers' attitude and behaviors [2], [7], [28], [40] found negative word-of-mouth responses to be less common when the firm is viewed as being receptive to complaints.

Much of the research relating to WOM has focused on negative, rather than positive, communication because it is related to consumers' complaints. The research indicates that the tendency to engage in negative WOM is influenced by several factors. [37] found that the tendency to engage in negative WOM was positively related to the level of dissatisfaction and negatively related to the consumer's perception of the retailer's responsiveness to complaints. It follows from justice theory that firms can restore consumers' propensity to spread positive recommendation by responding effectively to an inequitable service failure.

[18] mentioned that the measuring WOM brings three challenges. First, how does one gather the data? Because WOM information is usually exchanged in private conversation, direct observation traditionally has been difficult. Second, what aspects of WOM should be one measure? Third, since WOM is not exogenous, context becomes important. It is the objects of this paper meet these challenges by analyzing healthcare products and services complaints drawn from online stores, and measuring frequencies of incidents by categories.

\subsection{The Channel Choice of Consumer Complaints}

When a consumer experiences a problem with a product or service, there are normally three options for complaint resolution. First, consumers can take private action by dissociating themselves from the product or company, and/or spreading negative WOM. Second, consumers can take direct action by addressing a complaint directly to the company. Finally, consumers can take indirect public action by complaining to a third party [11], [21], [38], [29] found that 
consumers who sought redress chose an interactive channel rather than a remote channel. Consumers who wanted to get tangible compensation preferred a channel such as face-to-face or a phone channel. Consumers who wanted to vent their frustration leaned towards more asynchronous channels such as a written letter or e-mail.

Traditionally, third party redress may be the next logical step when consumers are dissatisfied with company responses. Third party redress is defined as "an individual or organization that is external to the consumer who initiates redress and is not directly involved in the dissatisfying transaction" [39]. Based on previous research, complaining to a third party is a rare event for consumers; less than 10 percent of total complaints go through the traditional third party redress channel [22]. However, online consumer opinion forums have proved to be a relatively convenient third party channel. In comparison with traditional third party routes, Internet third party websites such as opinion forums provide easy communication among consumers and high speed and spread of word-of-mouse (eWOM). [21] noted that a number of consumer complaint sites have a role as a central forum for consumers to share their bad experiences.

Related to healthcare services, [38] found that 55\% of the recommending patients had experience with the service of the physician. They concluded that a patient who avails the services of a physician as a result of recommendation by another patient is more loyal than one who comes through other sources. They explained that this finding supported the "Tiestrength Relationship Model" of [8] that strong tie sources, besides influencing the choice of a physician, also influence the patient's loyalty to the physician.

There is another dimension to consumer complaint behavior. Especially for customer-specific issues, consumer complaint behavior depends on the consumer's personal characteristics and styles [29], [39], [41], [41] categorized complainers into four types according to their response styles; people who take little or no action are categorized into passives; people who complain actively to the service provider/seller categorized into voicers; people who opt for private responses into irates; and people who engage in formal third party complaining into activists [29]. The data collection method used for this study prevents further analysis of these issues however.

\subsection{Healthcare industry's complaint}

Despite their potential importance, relatively few studies have examined dissatisfaction and complaint factors within medical services. General studies of complaints address consumers' complaint and complaint resolution rates about medical services less than other products and services [27]. [41] reported that consumers' perceived responsiveness of providers to complaints about medical services was the lowest of three categories of services, including grocery and autorepair. Examinations of the incidence of exit (e.g. switching medical providers) showed that between $49 \%$ [1] and $63.2 \%$ [41] choose the exit option instead of complaining to the seller.

While there has been relatively little research to date on analyzing consumers negative word-of-mouse(eWOM) complaints, there have been a number of studies that establish the relation between consumer attitude toward quality of healthcare information, healthcare delivery and customer satisfaction (see, for example, [10], [13], [26]). Attention has also been paid to the aspects of healthcare products and services which influence overall positive or negative evaluation by patients [17], [32]. These studies were considered in the identification of categories for this study.

\section{METHODOLOGY}

\subsection{Critical Incident Technique}

This study used the critical incident technique (CIT, see [14]) to identify the consumer complaint themes relating to online health products on e-retailer web sites. [3] defined critical incident as an "observable human activity that is complete enough in itself to permit inferences and predications to be made about the person performing the act". Critical incidents can be collected in different ways, but in the service research area, critical incidents are usually collected by asking respondents to tell a story about an experience they have had [19].

CIT has several benefits, including: collecting data from respondents in their own words, fitness for inductive (exploratory) research, and fitness for in-depth recording of events. CIT thus provides a rich set of data [19]. CIT has been criticized concerning reliability and validity problems. It is also possible that the researcher unconsciously misinterprets or misunderstands the respondents' words [17]. Such criticisms need to be kept in mind when interpreting results.

\subsection{Data Collection and Analyzing Procedure}

The purpose of this study is to qualitatively analyze consumers' service failure themes in the form of negative word-of-mouse (eWOM) relating to online healthcare products and services providers, with the object of categorizing the complaints. Figure 1 shows the four stages of data analyzing procedures employed.

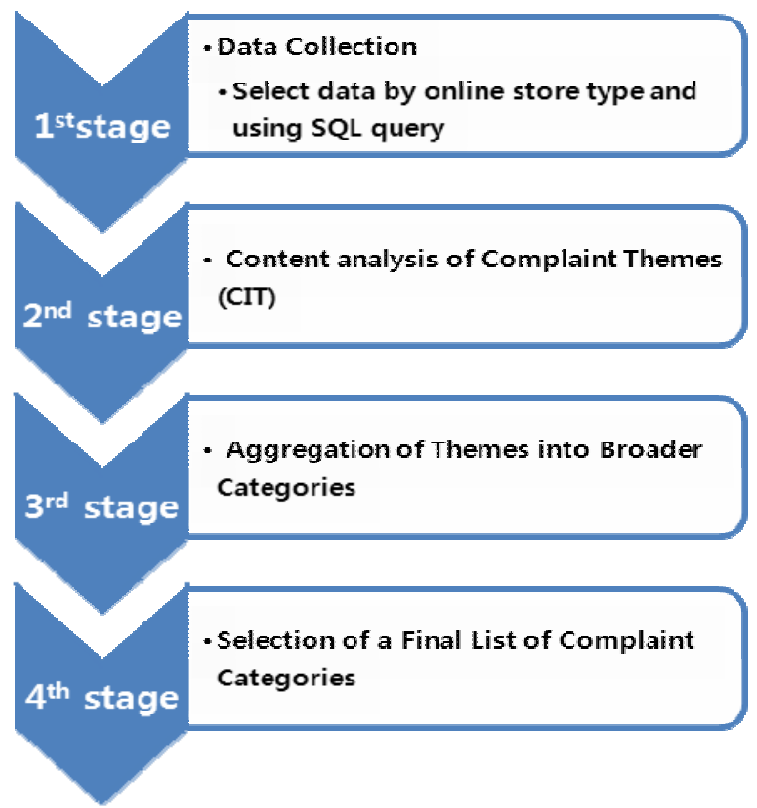

Fig. 1. Stages in data analyzing 
For the first stage, data were collected by consumer reviews on selected e-retailer sites for three years. Altogether 948 reviews were gathered. Structured Query Language (SQL) was used to identify relevant cases, using keywords, such as drug, health, healthcare, medicine, prescription, doctor, supplements and vitamins, and combinations thereof. After eliminating duplicate reviews and inappropriate reviews, a total of 784 reviews from 53 sites were selected for analysis. Of these, 202 were complaints, 18 were neutral comments and 562 were compliments

In the second stage of analysis, a content analysis of complaint themes using CIT was used. The 202 complaint reviews yield a total 462 complaint themes. For the third stage, the 462 complaint themes were classified into broad categories.

The fourth stage, the final classification of the incidents was conducted by 3 researchers. Aggregation of themes yielded 17 categories. Through a process of repeated and careful inspection of the consumer reviews (to assure cross validation), two researchers sorted the respective incidents according to similarity, and by consensus created six broad categories.

\section{RESULTS}

An overview of the complaints is presented in Table 1 . Consumers who bought health products from a medicine site comprised $48 \%$ of the total sample. Consumers who bought products through an optical site (e.g. contact lenses) comprised $23 \%$. Over half $(56 \%)$ consumers had bad experiences in the phase of using customer services. Only $12 \%$ of total complaints got the firm's service recovery efforts. This finding is consistent with previous study in that consumers' decision to engage in negative word-of-mouth (eWOM) may be dependent on firms' service recovery effort.

About $14 \%$ of consumers complained more than three times to the e-retailers. About $28 \%$ of health product buyers used a phone as their first complaint channel, while $20 \%$ used e-mail and $17 \%$ of consumers used third party websites. This result shows that consumers who want to get the service recovery, they prefer personal source at the first contact.

Interestingly, some $49 \%$ of consumers simply wanted to share for their bad experiences. According to the [25]'s research, refunds, credits, replacements, and apologies as main compensation methods used by service organizations. Moreover, most customers expect to be compensated for service failures [6]. Contrast to these research, this finding show that consumers just want to make bad WOM about their experiences. This result shed on the light to the characteristics of the eWOM on the virtual third party.

Table 2 shows each incident's frequency by subcategories. The objective of this study was to identify consumer complaint themes about online health sites. Among 462 incidents, 37 incidents $(8 \%)$ were classified into product related, 61 incidents $(13 \%)$ into ordering process related, 57 incidents $(12 \%)$ into payment/price related, 135 incidents $(29 \%)$ into delivery/shipping related, 167 incidents $(36 \%)$ into customer services related and 5 incidents $(1 \%)$ into privacy related. As stated, the lack of service failure recovery primarily induced consumers' complaint behavior and bad WOM.
Table 1. Descriptive statistics of complaint ( $\mathrm{N}=202)$

\begin{tabular}{|c|c|c|}
\hline Variables & $\mathbf{N}$ & $\%$ \\
\hline \multicolumn{3}{|l|}{ Site type } \\
\hline Medicine & 96 & 47.5 \\
\hline Medical supplies & 13 & 6.4 \\
\hline Allergy & 14 & 6.9 \\
\hline Optical & 51 & 25.2 \\
\hline Care & 28 & 13.9 \\
\hline \multicolumn{3}{|l|}{ Phase of complaint } \\
\hline Prepurchase product & 2 & 1.0 \\
\hline During ordering & 9 & 4.5 \\
\hline At the point of payment & 1 & 0.5 \\
\hline After purchasing/ & 63 & 31.2 \\
\hline Delivered product & 05 & 31.2 \\
\hline During using customer services & 110 & 54.5 \\
\hline \multicolumn{3}{|l|}{ Number of complaints } \\
\hline 1 & 39 & 19.3 \\
\hline 2 & 28 & 13.9 \\
\hline 3 & 28 & 13.9 \\
\hline More than three times & 30 & 14.9 \\
\hline \multicolumn{3}{|l|}{ First Complaint channel } \\
\hline E-mail & 41 & 20.3 \\
\hline Company website & 2 & 1.0 \\
\hline Third party website & 36 & 17.8 \\
\hline Phone call & 56 & 27.7 \\
\hline Letter/Fax & 3 & 1.5 \\
\hline \multicolumn{3}{|l|}{ Desired Compensation } \\
\hline Full refund & 28 & 13.9 \\
\hline $\begin{array}{l}\text { Partial refund } \\
\text { (refund overcharged part) }\end{array}$ & 7 & 3.5 \\
\hline Change with products & 7 & 3.5 \\
\hline Warning to the firm & 2 & 1.0 \\
\hline $\begin{array}{l}\text { Just share bad experience } \\
\text { (Negative WOM) }\end{array}$ & 99 & 49.0 \\
\hline $\begin{array}{l}\text { Fulfillment of their } \\
\text { Promise }\end{array}$ & 1 & 0.5 \\
\hline Cancel the order & 19 & 9.4 \\
\hline Return the product & 6 & 3.0 \\
\hline Stop spamming & 1 & 0.5 \\
\hline \multicolumn{3}{|l|}{ Recovering efforts } \\
\hline Yes & 24 & 11.9 \\
\hline No & 137 & 67.8 \\
\hline
\end{tabular}

\subsection{Product Related}

This category includes such incidents as product quality problems, false and misleading, and also the range of product available on the website. Since healthcare products are credence or search goods, product related problems are important for consumers. Some specific incidents were:

"Quality control is not working well on their tests. They do not test at the level they advertise at, and some of their tests do not even work."

"When we received this product, it did not work."

\subsection{Ordering Process Related}

The incidents in this category included such themes as ordering problems and difficulties, and non-fulfillment of contracts. Even though this category comprises a small portion of total incidents it has some uniqueness in comparison with 
general e-retailing goods. Health product consumers had some special difficulties in ordering their prescription drugs or products online. Some specific examples were:

Table 2. Complaint Themes as categorized ( $\mathrm{N}=462)$

\begin{tabular}{|c|c|c|c|}
\hline Categorization & Key complaint themes & $\mathbf{N}$ & $\%$ \\
\hline Product & Product quality related & 27 & 5.8 \\
\hline \multirow[t]{3}{*}{ Related } & $\begin{array}{l}\text { Information and advertising } \\
\text { related }\end{array}$ & 9 & 1.9 \\
\hline & Selection & 1 & 0.2 \\
\hline & Subtotal within a category & 37 & 8.0 \\
\hline Ordering Process & Ordering problem related & 26 & 5.6 \\
\hline \multirow[t]{3}{*}{ Related } & Hard to order & 12 & 2.6 \\
\hline & $\begin{array}{l}\text { Unfulfillment contract/ policy } \\
\text { problem }\end{array}$ & 23 & 5.0 \\
\hline & Subtotal within a category & 61 & 13.2 \\
\hline Payment/Price & $\begin{array}{l}\text { Overcharged/different price as } \\
\text { contract }\end{array}$ & 16 & 2.2 \\
\hline \multirow[t]{3}{*}{ Related } & Unfair Charge problem & 33 & 7.1 \\
\hline & Shipping fee problem & 14 & 8.0 \\
\hline & Subtotal within a category & 57 & 12.3 \\
\hline Delivery/Shipping & Not delivered & 63 & 13.6 \\
\hline \multirow[t]{3}{*}{ Related } & $\begin{array}{l}\text { Late/ delayed delivery as firm } \\
\text { noticed }\end{array}$ & 38 & 8.2 \\
\hline & $\begin{array}{l}\text { Not delivered as a } \\
\text { contract(part/broken/impaired) }\end{array}$ & 34 & 7.4 \\
\hline & Subtotal within a category & 135 & 29.2 \\
\hline Customer Service & Attitude & 30 & 6.5 \\
\hline \multirow[t]{4}{*}{ Related } & No responses about complain & 71 & 15.4 \\
\hline & Lack or inefficient service & 46 & 10.0 \\
\hline & Refund and return problem & 20 & 4.3 \\
\hline & Subtotal within a category & 167 & 36.1 \\
\hline Privacy & $\begin{array}{l}\text { Lack of protection about } \\
\text { personal information }\end{array}$ & 5 & 1.1 \\
\hline \multirow[t]{2}{*}{ Related } & Subtotal within category & 5 & 1.1 \\
\hline & Total & 462 & 100.00 \\
\hline
\end{tabular}

"I ordered contacts......They asked me to fax the prescription. I did ... But kept reading error. Called customer service. Said they could not ship, there was a discrepancy in the prescription."

"I faxed them a copy of my prescription and gave them my eye doctor's information. ... But they said my prescription was somehow "invalid", and after a lengthy and unproductive phone conversation with customer services, found that they were balking at my faxed prescription because the letterhead didn't look professional enough."
"My doctor had not responded to any of their attempts to reauthorize the Rx."

"I tried placing a prescription order over two weeks ago and got an email saying that they couldn't contact the doctor for the prescription."

"Even though I have a prescription that is good for one year, for some reason every few months either one of the pharmacies says it is out of date and needs my doctor's approval. I find this very tiresome!"

\subsection{Payment/Prices Related}

Incidents in this category included overcharge or charging difference prices than stated by the e-retailer's unfair charges, and shipping fee problems. Some specific verbal comments relating to unfair charge were:

"My insurance company sent the check to them by mistake. I called up their customer service and they said they would take care of it. However, they simply encashed the check, neither sending it back or forwarding it to me."

"I have yet to ask them to sort out the overcharge for not using my insurance to pay for the prescription."

"When I got my credit card bill I was shocked to see they charged me for the order that never showed up."

\subsection{Delivery/Shipping Related}

In this category, incidents identified were non-delivery, late/delayed delivery, and not delivered as contracted (broken, impaired). A recent study of online failures [23] stated that consumers noted delivery problems as the most frequently stated problem. Although consumers are concerned about Web site interactivity, the main concern for consumers is the delivery of the desired product or service in the manner desired. This category is critical in the healthcare industry where accurate and timely is important to consumer well-being.

Examples are:

"They shorted an order by 100 tablets, my wife has run out of the pills, they didn't ship refill on time."

"I still don't have my package; but, they have my money."

"When the package arrived three days later, there was only one item and a note stating that they never had the other two items to begin with."

\subsection{Customer Service related}

The fifth group of critical incidents merges from consumers' perceptions of e-retailers' customer service. In this category, incidents included: bad attitude, no responses to complaints, lack of or inefficient service, and refund and return problems.

"They screwed two important medical prescriptions which affected my health. I have ceased doing business with them."

"Received no e-mail confirmation, then the customer 'service' person was rude and obnoxious. “

"The customer assistance is not only clueless but extremely rude."

\subsection{Privacy related}

This group of incidents comprised the smallest portion of the total incidents. Lack of protection of personal information 
underlay most incidents.

"They accepted my billing address shipping address (both with Alaska zip codes) then VISA number and expiration date THEN - it comes back and says it will not ship to Alaska or Hawaii... They should tell you up front - NOT after you have entered all your information.

The relationship between categorized primary complaint themes and site type was analyzed using a chi-square test. The test was statistically significant at $p<0.001$. The results are shown in Table 3. There were differences between categorized primary complaint themes and site type. In the case of medicine sites, site users experienced more payment/price related complaint themes than other themes as their primary complaint. For allergy sites, users were experienced more ordering process related complaints in comparison with other themes. In the optical sites, customer related complaints were more likely to occur than other complaint themes. In the case of medical supplies and fitness sites, product related complaints were more likely to occur.

Table 3. Chi-square analysis of site type and primary complaint themes' category $(\mathrm{N}=202)^{*}$

\begin{tabular}{lllllll}
\hline Variables & $\mathbf{1}$ & $\mathbf{2}$ & $\mathbf{3}$ & $\mathbf{4}$ & $\mathbf{5}$ & $\mathbf{6}$ \\
\hline Medicine & 6 & 10 & 18 & 45 & 15 & 2 \\
& $(31.6)$ & $(43.5)$ & $(66.7)$ & $(54.9)$ & $(31.9)$ & $(50.0)$ \\
Allergy & 0 & 3 & 2 & 6 & 3 & 0 \\
& $(0.0)$ & $(13.0)$ & $(7.4)$ & $(7.3)$ & $(6.4)$ & $(0.0)$ \\
Optical & 2 & 5 & 3 & 22 & 18 & 1 \\
& $(10.5)$ & $(21.7)$ & $(11.1)$ & $(26.8)$ & $(38.3)$ & $(25.0)$ \\
Medical & 5 & 0 & 2 & 4 & 2 & 0 \\
Supplies & $(26.3)$ & $(0.0)$ & $(7.4)$ & $(4.9)$ & $(4.3)$ & $(0.0)$ \\
Care & 6 & 5 & 2 & 5 & 9 & 1 \\
& $(31.6)$ & $(21.7)$ & $(7.4)$ & $(6.1)$ & $(19.2)$ & $(25.0)$ \\
Total & 19 & 23 & 27 & 82 & 47 & 4 \\
(within & $(100)$ & $(100)$ & $(100)$ & $(100)$ & $(100)$ & $(100)$ \\
category) & & & & & & \\
\% of & 9.4 & 11.4 & 13.4 & 40.6 & 23.3 & 2.0 \\
Total & & & & & & \\
\hline
\end{tabular}

*Note 1: Product related; 2-ordering process related; 3payment/price related;4-delivery/shipping related; 5-customer service related; 6; privacy related

**Note 2: all result is statistically significant at the level of 0.001

\section{CONCLUSIONS}

The purpose of this study is to qualitatively analyze and categorize service failure themes (complaint themes) via online consumers' complaints and to identify complaint themes relating to health products in online stores. A total of 462 complaint themes (for primary and secondary complaints) were analyzed in five healthcare website types. Using CIT methods, 17 consumer complaint themes were grouped and then finally categorized into six categories. In the process of conducting this exploratory study, the frequencies of characteristics and the differences about complaint themes were analyzed according to site types.

These results showed that they were consistent with previous study in that consumers' decision to engage in negative wordof-mouse (eWOM) may be dependent on firms' service recovery effort. It was identified over half consumers had experience service failure in the phase of using customer services. Also the delivery and customer services were critical issues when consumer made negative WOM. Accordingly, the understanding we have achieved from offline service failure/recovery research is highly relevant online.

Results identified that major complaint theme differed according to site type. For example, it was shown that medicine site consumers experienced more payment/price related complaints than other complaint themes. The results of the present study can therefore help health products e-retailers of various types to identify customers' prime sources of dissatisfaction, and take appropriate steps.

For health care practitioners, these results can give some insights. According to the site type and service phases, consumers experience different extent of service failure. To prevent spreading of bad word-of-mouse(eWOM), healthcare practitioners should improve their service phases related with major complaint themes which were identified in this research.

It should be noted that the present study is subject to a number of limitations. First, the data were analyzed through posted consumer complaints, rather than a conducted survey. The chosen method has an advantage from the perspective of lower cost and the elimination of reliance on recall (natural setting), but respondents are self-selected. Generalization from results is therefore an issue. Despite the large number of postings in the sample, there were a limited number of consumer reviews relating to complaints, and the some consumers' reviews sometimes deviated from the purpose of the study. Data mining techniques could augment this study by drawing on larger numbers of cases, and it is recommended that validation of findings by a follow-up survey be conducted.

\section{REFERENCES}

[1] T. W. Andreassen, "Antecedents to Satisfaction with Service Recovery," European Journal of Marketing, vol. 34 , no. $1 / 2,2000$, pp. 156-175.

[2] A. A. Bailey, "Thiscompanysucks.com: The Use of the Internet in Negative Consumer-to-consumer Articulations," Journal of Marketing Communications, vol. 10, September, 2004, pp. 169-182.

[3] M. J., Bitner, B. H. Booms, and M. S. Tetreault, "The Service Encounter: Diagnosing Favorable and Unfavorable Incidents," Journal of Marketing, vol. 54, January, 1990, pp. 71-84.

[4] P. H. Bloch, D. L. Sherrell, and N. M. Ridgway, "Consumer Search: An Extended Framework", Journal of Consumer Research, vol. 13, June, 1986, pp. 119-126.

[5] J. G. Blodgett, D. H. Granbois, G. Rockney and R. G. Walters, "The Effects of Perceived Justice on Complainants' Negative Word-of-Mouth Behavior and Repatronage Intentions," Journal of Retailing, vol. 69, no. 4, 1993, pp. 399-428.

[6] J. G. Blodgett, D. J. Hill, and S. S. Tax, S.S. "The Effects of Distributive, Procedural, and Interactional Justice on 
Postcomplaint Behavior," Journal of Retailing, vol. 73, no. 2, 1997, pp. 185-210.

[7] P. F. Bone, "Word-of-mouth Effects on Short-term and Long-term Product Judgments," Journal of Business Research, vol. 32, no. 3, 1995, pp. 213-223.

[8] J. J. Brown, and P. H. Reingen, "Social Ties and Wordof-mouth Referral Behavior," Journal of Consumer Research, vol. 14, December, 1987, pp. 350-362.

[9] Y. Cho, I. Im, and R. Hiltz, "The Impact of E-service Failure and Customer Complaints on Electronic Commerce Customer Relationship Management,” Journal of Consumer Satisfaction and Dissatisfaction and Complaining Behavior, vol. 16, 2003, pp. 106-118.

[10] R. J. W. Cline, and K. M. Haynes, "Consumer Health Information Seeking on the Internet: The State of the Art," Health Education Research, vol. 16, no. 6, 2001, pp. 671-692.

[11] R. L. Day, and E. L. Jr. Landon, Towards a Theory of Consumer Complaining Behavior, in Woodside, A., Sheth, J. and Bennett, P. (Eds), Consumer and Industrial Buying Behavior, North Holland Publishing Company, Amsterdam, 1977.

[12] H. Estelami, "Competitive and Procedural Determinants of Delight and Disappointment in Consumer Complaint Outcomes," Journal of Service Research, vol. 2, no. 3, 2000, pp. 285-300.

[13] G. Eysenbach, J. Powell, O. Kuss, and E. Sa, "Empirical Studies Assessing the Quality of Health Information for Consumers on the World Wide Web', JAMA, vol. 287, no. 20, 2002, pp. 2691-2700.

[14] J. C. Flanagan, "The Critical Incident Techniques," Psychological Bulletin, vol. 51, July, 1954, pp. 327-358.

[15] S. Fox, Health topics. Pew Internet \& American Life Project: Online Life Report, 2011.

[16] S. Fox, The social life of health information. Pew Internet \& American Life Project: Online Life Report, 2011.

[17] M. Gabbott, and G. Hogg, "The Glory of Stories: Using Critical Incidents to Understand Service Evaluation in the Primary Healthcare Context," Journal of Marketing Management, vol. 12, no. 6, 1996, pp. 493-503.

[18] D. Godes, and D. Mayzlin, "Using Online Conversations to Study Word-of-mouth Communication', Marketing Science, vol. 23, Fall, 2004, pp. 545-560.

[19] D. D. Gremler, "The Critical Incident Techniques in Service Research," Journal of Service Research, vol. 7, no. 1,2004 , pp. $65-89$.

[20] C. Gronroos, (1988), "Service Quality: The Six Criteria of Good Perceived Service Quality," Review of Business, vol. 9, Winter, 1988, pp. 10-13.

[21] L. J. Harrison-Walker, "E-complaining: A Content Analysis of an Internet Complaint Forum," The Journal of Service Marketing, vol. 15, no. 4/5, 2001, pp. 397-412.

[22] J. M. Hogarth, M. English, and M. Sharma, "Consumer Complaints and Third Parties: Determinants of Consumer Satisfaction with Complaint Resolution Efforts," Journal of Consumer Satisfaction, Dissatisfaction and complaining Behavior, vol. 14, 2001, pp. 74-87.
[23] B. B. Holloway, and S. E. Beatty, "Service Failure in Online Retailing: A Recovery Opportunity," Journal of Service Research, vol. 6, no. 1, 2003, pp. 92-105.

[24] E. Katz, and P. H. Lazarsfeld, Personal Influence, Glencoe, IL: Free Press, 1955.

[25] S. W. Kelly, K. D. Hoffman, and M. A. Davis, "A Typology of Retail Failures and Recoveries," Journal of Retailing, vol. 69, Winter, 1993, pp. 429-452.

[26] P. Kim, T. R. Eng, M. J. Deering, and A. Maxfield, "Published Criteria for Evaluating Health Related Web Sites: Review,” BMJ, vol. 318, 1999, pp. 647-649.

[27] J. Kolodinsky, "Complaints, Redress, and Subsequent Purchases of Medical Services by Dissatisfied Consumers," Journal of Consumer Policy, vol. 16, no. 2, 1993, pp. 193-214.

[28] W. G. Mangold, F. Miller, and G. R. Brockway, "Wordof-mouth Communication in the Service Marketplace," The Journal of Services Marketing, vol. 13, no. 1, 1999, pp. 73-89.

[29] A. S. Mattila, and J. Wirtz, "Consumer Complaining to Firms: The Determinants of Channel Choice," The Journal of Service Marketing, vol. 18, no. 2, 2004, pp. 147-155.

[30] J. G. Ш Maxham, and R. G. Netemeyer, "Modeling Customer Perceptions of Complaint Handling over Time: The Effects of Perceived Justice on Satisfaction and Intent," Journal of Retailing, vol. 78, 2002, pp. 239-252.

[31] M. A. McCollough, L. L. Berry, and M. S. Yadav, "An Empirical Investigation of Customer Satisfaction after Service Failure and Recovery," Journal of Service Research, vol. 3, no. 2, 2000, pp. 121-137.

[32] D. E. Murfin, B. S. Bado, and A. Diamantopoulos, A. "Perceived Service Quality and Medical Outcome: An Interdisciplinary Review and Suggestions for Future Research," Journal of Marketing Management, vol. 11, 1995, pp. 97-117.

[33] K. B. Murray, "A Test of Services Marketing Theory: Consumer Information Acquisition Activities," Journal of Marketing, vol. 55, no. 1, 1991, pp. 10-25.

[34] V. A. Nasir, "E-consumer Complaints about On-line Stores," Journal of Consumer Satisfaction and Dissatisfaction and Complaining Behavior, vol. 17, 2004, pp. 68-87.

[35] R. L. Oliver, "A Cognitive Model of the Antecedence and Consequences of Satisfaction Decisions," Journal of Marketing Research, vol. 17, September, 1980, pp. 46-49.

[36] A. Parasuraman, V. A. Zeithaml, and L. L. Berry, "A Conceptual Model of Service Quality and its Implications for Future Research,” Journal of Marketing, vol. 49, Fall, 1985, pp. 41-50.

[37] M. L. Richins, "Negative Word-of-mouth by Dissatisfied Consumers: A Pilot Study," Journal of Marketing, vol. 47, no. 1,1983 , pp. $68-78$.

[38] P. B. Salgaonkar, and N. M. Reader, "Patient as a Source of Recommendation and its Influence on Another Patient's Royalty to the Physician: An Exploratory Empirical Study," Journal of Consumer Satisfaction and Dissatisfaction and Complaining Behavior, vol. 17, 2004, pp. 16-26. 
[39] J. Singh, "Consumer Complaint Intentions and Behavior: Definitional and Taxonomical Issues," Journal of Marketing, vol. 52, 1988. pp. 93-107.

[40] J. Singh, "Voice, Exit and Negative Word-of-mouth Behaviors: An Investigation across Three Service Categories," Journal of the Academy of Marketing Science, vol. 18, no. 1, 1990a, pp. 1-15.

[41] J. Singh, A Typology of Consumer Dissatisfaction Response Style," Journal of Retailing, vol. 66, no. 1, 1990b, pp. 57-97.

[42] R. A. Spreng, G. D. Harrell, and R. D. Mackoy, "Service Recovery: Impact on Satisfaction and Intentions," The Journal of Services Marketing, vol. 9, no. 1, 1995, pp. 1523.

[43] J. E. Stafford, J. "Effects of Group Influence on Consumer Brand Preferences," Journal of Marketing Research, vol. 3, no. 1, 1966, pp. 68-75.

[44] B. Stauss, and C. Friege "Regaining Service Customers," Journal of Service Research, vol. 1, May, 1999, pp. 34761.

[45] S. S. Tax, and S. W. Brown, "Recovering and Learning from Service Failure," Sloan Management Review, vol. 39, Fall, 1998, pp. 75-88.

[46] M. Venkatesan, "Experimental Study of Consumer Behavior, Conformity and Independence," Journal of Marketing Research, vol. 3, no. 4, 1966, pp. 384-387.

[47] R. A. Westbrook, Product/consumption-based Affective Responses and Postpurchase Process," Journal of Marketing Research, vol. 24, no. 3, 1987, pp. 258-270.

[48] W. R. Wilson, and R. A. Peterson, "Some Limits on the Potency of Word-of-mouth Information," Advances in Consumer Research, vol. 16, 1989, pp. 23-29.

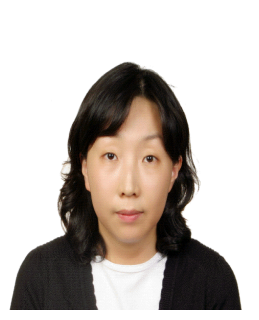

\section{Sujin Oh}

She received the Ph.D in Consumer Sciences \& Retailing (major in Consumer Behavior) from Purdue University, USA. She has been working as an assistant professor of Sookmyung Women's University, Korea. Her main research interests include consumer's online behavior and customer's experience management, multichannel marketing and consumer policy. 